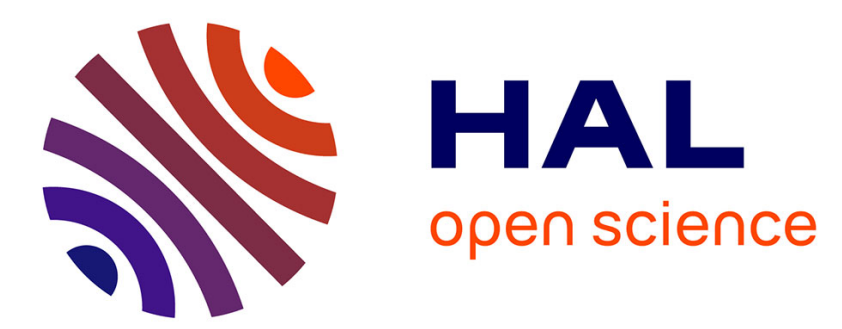

\title{
The follicular sensitivity in vitro to maturation-inducing hormones in rainbow trout, Salmo gairdneri: Role of oestradiol-17 $\beta$
}

\author{
Bernard Jalabert, Alexis Fostier
}

\section{To cite this version:}

Bernard Jalabert, Alexis Fostier. The follicular sensitivity in vitro to maturation-inducing hormones in rainbow trout, Salmo gairdneri: Role of oestradiol-17 $\beta$. Aquaculture, 1984, 43 (1-3), pp.1-11. 10.1016/0044-8486(84)90004-8 . hal-01601161

\section{HAL Id: hal-01601161 \\ https://hal.science/hal-01601161}

Submitted on 2 Jun 2020

HAL is a multi-disciplinary open access archive for the deposit and dissemination of scientific research documents, whether they are published or not. The documents may come from teaching and research institutions in France or abroad, or from public or private research centers.
L'archive ouverte pluridisciplinaire HAL, est destinée au dépôt et à la diffusion de documents scientifiques de niveau recherche, publiés ou non, émanant des établissements d'enseignement et de recherche français ou étrangers, des laboratoires publics ou privés.

\section{다(1)(2)}

Distributed under a Creative Commons Attribution - ShareAlikel 4.0 International 
Elsevier Science Publishers B.V., Amsterdam - Printed in The Netherlands

\title{
THE FOLLICULAR SENSITIVITY IN VITRO TO MATURATION-INDUCING HORMONES IN RAINBOW TROUT, SALMO GAIRDNERI: ROLE OF OESTRADIOL-17 $\beta$
}

\author{
BERNARD JALABERT and ALEXIS FOSTIER
}

With the technical assistance of MICHELINE HEYDORFF and ODILE MARCUZZI

I.N.R.A., Laboratoire de Physiologie des Poissons, Campus de Beaulieu, 35042 Rennes, Cédex (France)

\begin{abstract}
Jalabert, B. and Fostier, A., 1984. The follicular sensitivity in vitro to maturation-inducing hormones in rainbow trout, Salmo gairdneri: role of oestradiol-17 $\beta$. Aquaculture, $43: 1-11$.

Trout ovaries were processed in vitro to determine relationships between the following parameters - oocyte sensitivity to the maturational steroid $17 \alpha$-hydroxy-20 $\beta$ dihydroprogesterone $(17 \alpha, 20 \beta-\mathrm{OH}-\mathrm{P})$; follicular sensitivity to the maturational gonadotropin s-GtH; inhibitory potency of exogenous oestradiol-17ß (E2) during s-GtH-induced maturation; and level of E2 in the plasma. The sensitivity to hormones was estimated by the median efficient dose (MED) for oocy te maturation in vitro.

The peripheral migration of the germinal vesicle coincided with an increase in oocyte sensitivity to $17 \alpha, 20 \beta-O H-P$. A significant correlation was observed between plasma E2 level and the follicular sensitivity to s-GtH, but not between plasma $\mathrm{E} 2$ and the oocyte sensitivity to $17 \alpha, 20 \beta-\mathrm{OH}-\mathrm{P}$. It was concluded that the peripheral migration of the GV is a morphological event which coincides with an increase in oocyte sensitivity, and that E2 is a physiological regulator of follicular sensitivity to GtH.
\end{abstract}

\section{INTRODUCTION}

In salmonids the maturational gonadotropin $\mathrm{GtH}$ appears to control final oocyte maturation (resumption of meiosis) by inducing the intrafollicular synthesis of $17 \alpha$-hydroxy-20 $\beta$-dihydroprogesterone $(17 \alpha, 20 \beta-\mathrm{OH}$ P), a steroid which is believed to be the specific mediator of oocyte maturation in this family (for review see Jalabert, 1976; Fostier and Jalabert, 1982; Goetz, 1983). The appearance of follicular ability allowing oocyte maturation to occur in vitro within the intact follicle in response to exogenous hormones seems to coincide roughly with known morphological and endocrinological events which appear progressively towards the end of vitellogenesis: the migration of the germinal vesicle (GV) to the oocyte periphery and the decrease in plasma level of oestradiol-17 $\beta$ (E2) (Fostier and Jalabert, 1982). 
E2 is considered as the main ovarian steroid hormone controlling hepatic vitellogenin synthesis in lower vertebrates. Its final decrease (Fostier et al., 1978) could be simply related to the completion of vitellogenesis. It could also be an important signal initiating another ovarian event. E2 has been shown to decrease the efficiency of GtH to induce intrafollicular oocyte maturation in vitro (Jalabert, 1975). This effect was shown recently to be related to a significant inhibition of $17 \alpha, 20 \beta-\mathrm{OH}-\mathrm{P}$ output by incubated follicles (Jalabert and Fostier, 1984).

The aim of the present work is to confirm, on a statistical basis, the link between the morphological stage of oocytes (GV position), E2 plasma level of donor fishes, and the follicular sensitivity to hormones in vitro.

The follicular sensitivity can be quantitatively evaluated in vitro from the morphological maturation response of oocytes incubated within intact follicles in the presence of an exogenous hormone, using the median efficient dose (MED), which is the dose inducing 50 per 100 of maturation (Jalabert et al., 1974). When $17 \alpha, 20 \beta-O H-P$ is used, it can be assumed that the observed MED reflects only oocyte sensitivity per se although metabolization by the follicular layers may occur. When a gonadotropin is assayed, the observed MED depends both on the oocyte sensitivity to the maturation-inducing steroid (MIS) and on the sensitivity to the gonadotropin of steroidogenic cells which produce the MIS. This steroidogenic response was recently shown to be mediated by c-AMP, and its amplitude, depending on the stage, appeared to be regulated at a step beyond c-AMP production (Fostier and Jalabert, 1983).

The evaluation of the MED for intrafollicular oocyte maturation in vitro of $17 \alpha, 20 \beta-\mathrm{OH}-\mathrm{P}$ or of the salmon maturational gonadotropin s-GtH may give a useful indication about the two levels of follicular sensitivity as defined above. The first stage of our work was to look for a possible relationship between these two estimates of follicular sensitivity at different oocyte stages.

\section{MATERIAL AND METHODS}

\section{Animals}

Female rainbow trout (Salmo gairdneri), 3 years old, weighing around $1.5 \mathrm{~kg}$ were used. They belonged to an "hivermal" strain (spawning between 15 October and 15 January), and were previously reared at the experimental fish farm of Gournay-sur-Aronde (Oise). These fish were acclimated for at least 1 month before any experiment in small tanks $\left(4 \mathrm{~m}^{2}\right)$ supplied with recirculated water at constant temperature $\left(12^{\circ} \mathrm{C}\right)$, and were fed twice a day with commercial pellets. During the expected "spawning period" all the fishes were anesthetized (2-phenoxy-ethanol $0.3 \%$ in water) once weekly in order to check for the oocyte stage determined by observation of a few follicles squeezed out by abdominal stripping. The fish that 
had oocytes at the appropriate stage were killed by a knock on the head, then bled by puncture in the caudal vein, using a syringe treated with sodium heparinate $(700 \mathrm{UI} / \mathrm{ml}$ in isotonic saline). Plasma samples were prepared by centrifugation and kept frozen $\left(-20^{\circ} \mathrm{C}\right)$ until assay for oestradiol-17 $\beta$ by radioimmunoassay. The ovaries were removed and kept on ice for subsequent dissection.

\section{Oocyte stage}

Three morphological stages were defined by observation with a stereomicroscope $(\times 10)$ using transmitted light (Fig. 1).

- End of vitellogenesis (EV). The germinal vesicle (GV) is not visible at this time, but polarized cytoplasm can be observed as a dark cloud (or a white spot by the naked eye).

- Subperipheral germinal vesicle (SP-GV). The GV begins to appear at the oocyte periphery and can be observed as a diffuse clear spot at the center of the dark cytoplasm.

- Peripheral germinal vesicle (P-GV). The GV appears as a clear spot with a precise circular outline (around $200 \mu \mathrm{m}$ in diameter), close to the chorion, at the center of the cytoplasm.

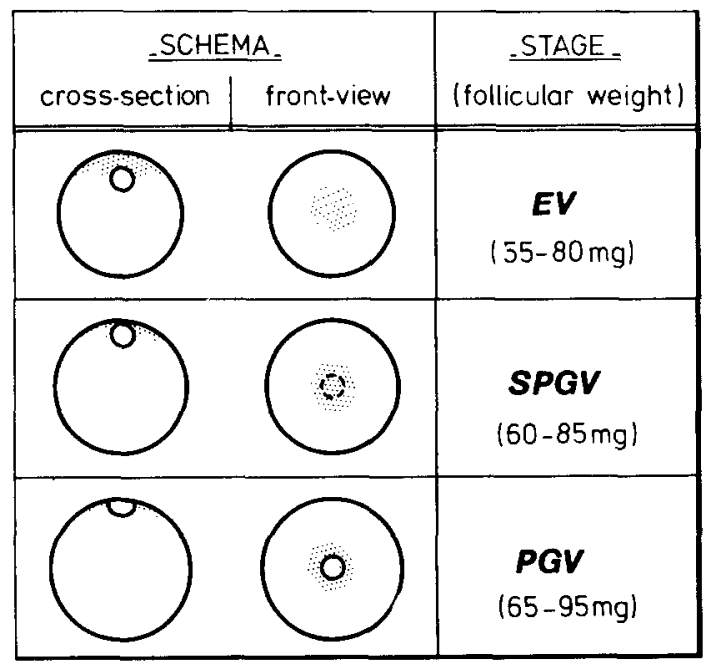

Fig. 1. Schematic representation of the oocyte stages considered for the experiments. EV: end of vitellogenesis; SP-GV: subperipheral germinal vesicle; P.GV: peripheral germinal vesicle. GV is represented as a small circle and the polarized cytoplasm by the dotted zone. 


\section{Incubation}

Small clusters of two to six follicles within interstitial tissue were distributed at the rate of 25 follicles per vial containing $2 \mathrm{ml}$ of trout balanced salt solution or TBSS buffered by HEPES-NaOH $0.04 \mathrm{M}, \mathrm{pH} 8$ (Jalabert and Fostier, 1984). A 2-h pre-incubation was first performed at $12.5^{\circ} \mathrm{C}$ either in control TBSS or in TBSS containing oestradiol-17 $\beta$ at the appropriate concentration $(1$ or 0.2 or $0.04 \mu \mathrm{g} / \mathrm{ml}$ ). Either $17 \alpha$,$20 \beta-\mathrm{OH}-\mathrm{P}$ or salmon gonadotropin (s-GtH) was then added at various concentrations using ethanol ( $5 \mu \mathrm{l}$ per vial) and TBSS ( $50 \mu \mathrm{l}$ per vial) respectively, as a vehicle. The whole incubation process lasted $48 \mathrm{~h}$ with $17 \alpha$,$20 \beta-\mathrm{OH}-\mathrm{P}$ and $72 \mathrm{~h}$ with s-GtH under a renewed atmosphere of $50 \% \mathrm{~N}_{2}-$ $50 \% \mathrm{O}_{2}$.

\section{Hormones}

$17 \alpha$-Hydroxy-20 $\beta$-dihydroprogesterone (pregnen- 4 one- $17 \alpha, 20 \beta$-diol-3 one, abbreviated $17 \alpha, 20 \beta-O H-P)$ was prepared according to Fostier et al. (1973). Oestradiol-17 $\beta$ was purchased from steraloids (U.S.A.). The salmon maturational gonadotropin s-GtH was prepared from Oncorhynchus tshawytscha pituitaries as described by Breton et al. (1978) using intrafollicular maturation in vitro of trout oocytes as a bioassay (Jalabert et al., 1974).

Determination of hormonal efficiency on intrafollicular oocyte maturation in vitro

The median efficient dose (MED) of a hormone is defined as the theoretical dose expected to induce $50 \%$ of the maximal response and it has already been used to quantify the maturation response of trout oocytes in vitro (Jalabert et al., 1974; Jalabert, 1975). In the present experiments the sigmoid curve representing the proportions of mature oocytes as a function of the logarithm of the dose was also linearized by the method of maximum likelihood estimation (Finney, 1962) after logit transformation (instead of probit transformation) (Finney, 1964) of the proportion of maturation responses for each dose administered in duplicate vials. This allowed for a precise estimation of the MED and related confidence limits.

The relative efficiency of s-GtH in the presence of $E_{2}$ is defined as the ratio between the MED of s-GtH alone and the MED of s-GtH in the presence of $E_{2}$ (Jalabert, 1975).

\section{Radioimmunoassay of oestradiol-17 $\beta$ in plasma}

This was performed as described by Fostier et al. (1978). Samples were extracted twice with $2 \mathrm{ml}$ cyclohexane : ethylacetate (50:50), then chrom- 
atographed on Sephadex LH-20 columns $(0.5 \times 8 \mathrm{~cm})$ with benzene : methanol $(85: 15)$ as eluant. However, the antibody was precipitated overnight at $4^{\circ} \mathrm{C}$ by adding $2 \mathrm{ml}$ of polyethyleneglycol (Merck, MW 5000-7000) in phosphate buffer $25 \% \mathrm{w} / \mathrm{w}$, instead of using a second antibody (Schiller et al., 1976).

\section{RESULTS}

Table I shows the median values concerning the MED of $17 \alpha, 20 \beta-\mathrm{OH}-\mathrm{P}$ and s-GtH, and the level of oestradiol-17 $\beta$ in the plasma of donor fishes. Although these parameters appear to exhibit some covariation according to the oocyte stage, they also exhibit a wide range of variation between fishes which requires further analysis.

\section{TABLE I}

Median values of the MED of $17 \alpha, 20 \beta-\mathrm{OH}-\mathrm{P}$ and s-GtH, and of the levels of oestradiol$17 \beta$ of donor fishes, according to the oocyte stage (numbers between parentheses indicate the range of observed values; $n$ is the number of observations)

\begin{tabular}{lccc}
\hline Oocyte stage & \multicolumn{2}{l}{$\begin{array}{l}\text { Median efficient dose }(\mathrm{ng} / \mathrm{ml}) \\
\text { in vitro of: }\end{array}$} & $\begin{array}{l}\text { Oestradiol-17 } \beta \text { in } \\
\text { plasma }(\mathrm{ng} / \mathrm{ml})\end{array}$ \\
\cline { 2 - 3 } & $17 \alpha, 20 \beta-\mathrm{OH}-\mathrm{P}$ & $\mathrm{s}-\mathrm{GtH}$ & \\
\hline End of & 78 & 81 & 18 \\
vitellogenesis & $(17-416)$ & $(50--393)$ & $(6-43)$ \\
(EV) & $n=12$ & $n=9$ & $n=12$ \\
Subperipheral & 66 & 32 & 17 \\
germinal vesicle & $(10-107)$ & $(9-275)$ & $(5-29)$ \\
(SP-GV) & $n=5$ & $n=9$ & $n=9$ \\
Peripheral & 13 & 24 & 8.5 \\
germinal vesicle & $(3-4)$ & $(8-24)$ & $(2.8-25)$ \\
(P-GV) & $n=10$ & $n=12$ & $n=11$ \\
\hline
\end{tabular}

Relationship between the follicular sensitivity to $17 \alpha, 20 \beta-O H-P$ and to $\mathrm{s}-G t H$, according to the oocyte stage

Fig. 2 shows the relationship between the MED of $17 \alpha, 20 \beta-\mathrm{OH}-\mathrm{P}$ and $\mathrm{s}-\mathrm{GtH}$ in individual females at different oocyte stages. Generally, all stages combined, the correlation between these two criteria of sensitivity is highly significant $(R=0.70)$ and a mean linear regression line can be drawn between log-transformed data. However, if two populations are considered separately, i.e., the population taken at EV stage and the population taken at P-GV stage, each one shows a significant correlation between both sen- 
sitivity parameters but exhibits a distinct regression line. A covariance analysis shows that for an equal apparent response to s-GtH, stage P-GV is characterized by a lower MED (highly significant) to $17 \alpha, 20 \beta-\mathrm{OH}-\mathrm{P}$ than the EV stage, which means an increased sensitivity to $17 \alpha, 20 \beta-O H-P$.

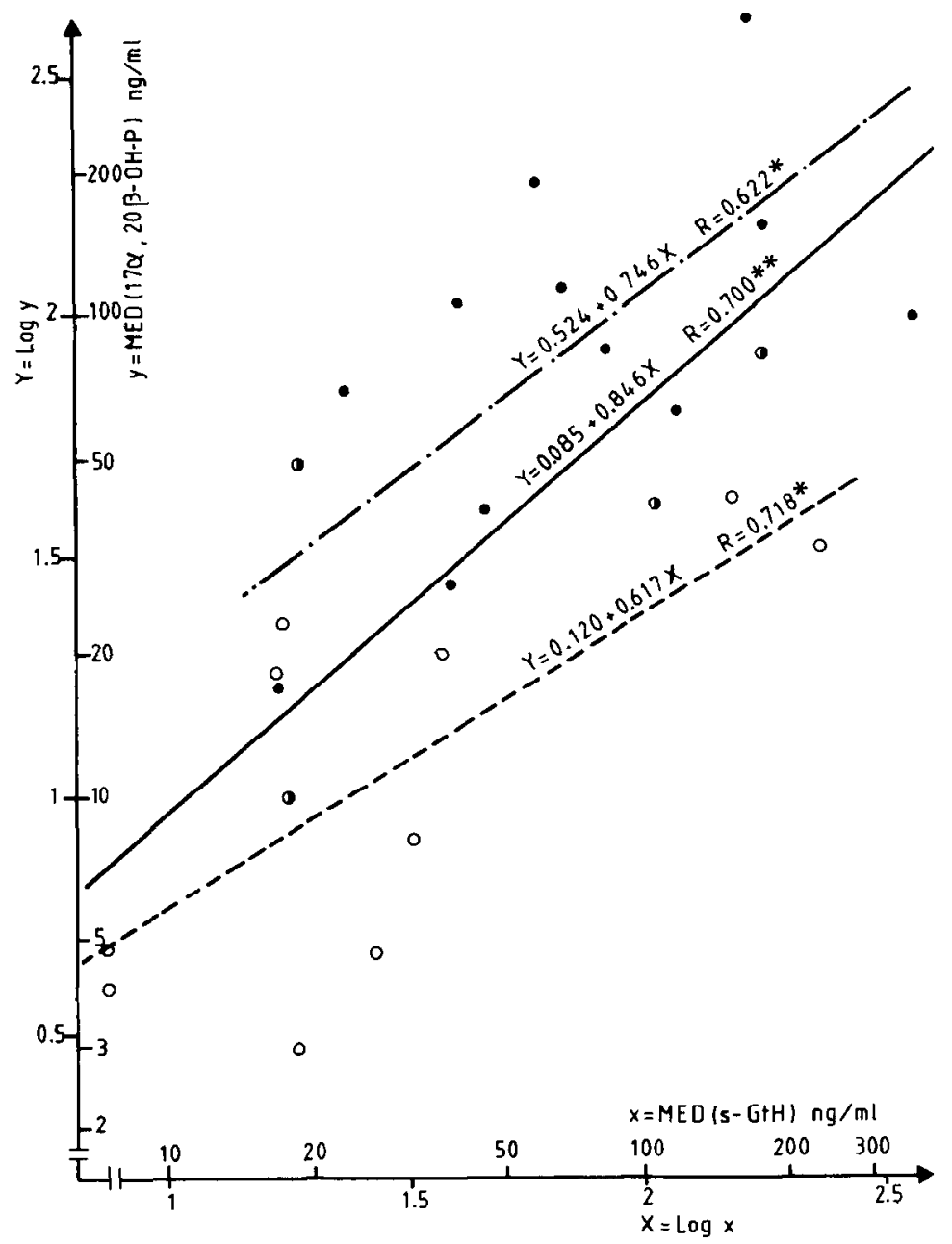

Fig. 2. Relationship between the median efficient dose (MED) of s-GtH and the MED of $17 \alpha, 20 \beta-O H-P$ for intrafollicular oocyte maturation, after logarithmic transformation of the data. Each experimental point is obtained from an incubation performed with follicles from one female exhibiting oocytes at one of the following stages: $\bullet=E V=$ end of vitellogenesis; $\bullet=\mathrm{SP}-\mathrm{GV}=$ subperipheral germinal vesicle; $0=\mathrm{P}-\mathrm{GV}=$ peripheral GV. Correlation coefficient $R$ significant $\left({ }^{*}\right)$ or highly significant $\left({ }^{* *}\right)$. 
Relationship between the follicular sensitivity to $17 \alpha, 20 \beta-O H-P$ or to $s-G t H$ and the level of oestradiol-17 $\beta$ in the plasma of donor fishes

No significant correlation was found between $\mathrm{E} 2$ level in the plasma of donor fishes, whatever the oocyte stage, and the MED of $17 \alpha, 20 \beta-\mathrm{OH}-\mathrm{P}$ in vitro, whereas a significant correlation $(R=0.43)$ can be observed between plasma E2 and the MED of s-GtH (Fig. 3).

Relationship between the efficiency of E2 to inhibit s-GtH-induced maturation and the follicular sensitivity to $s-G t H$

Fig. 4 shows the relationship between the relative efficiency of s-GtH in the presence of $\mathrm{E} 2$ in vitro (which is an indication of the inhibitory potency of E2 upon s-GtH-induced maturation) and the control MED of s-GtH. The general tendency appears to be that the inhibitory effect of E2 is even more important since the follicular sensitivity to s-GtH is higher (i.e., the MED is lower) to any dose of E2. A regression line can

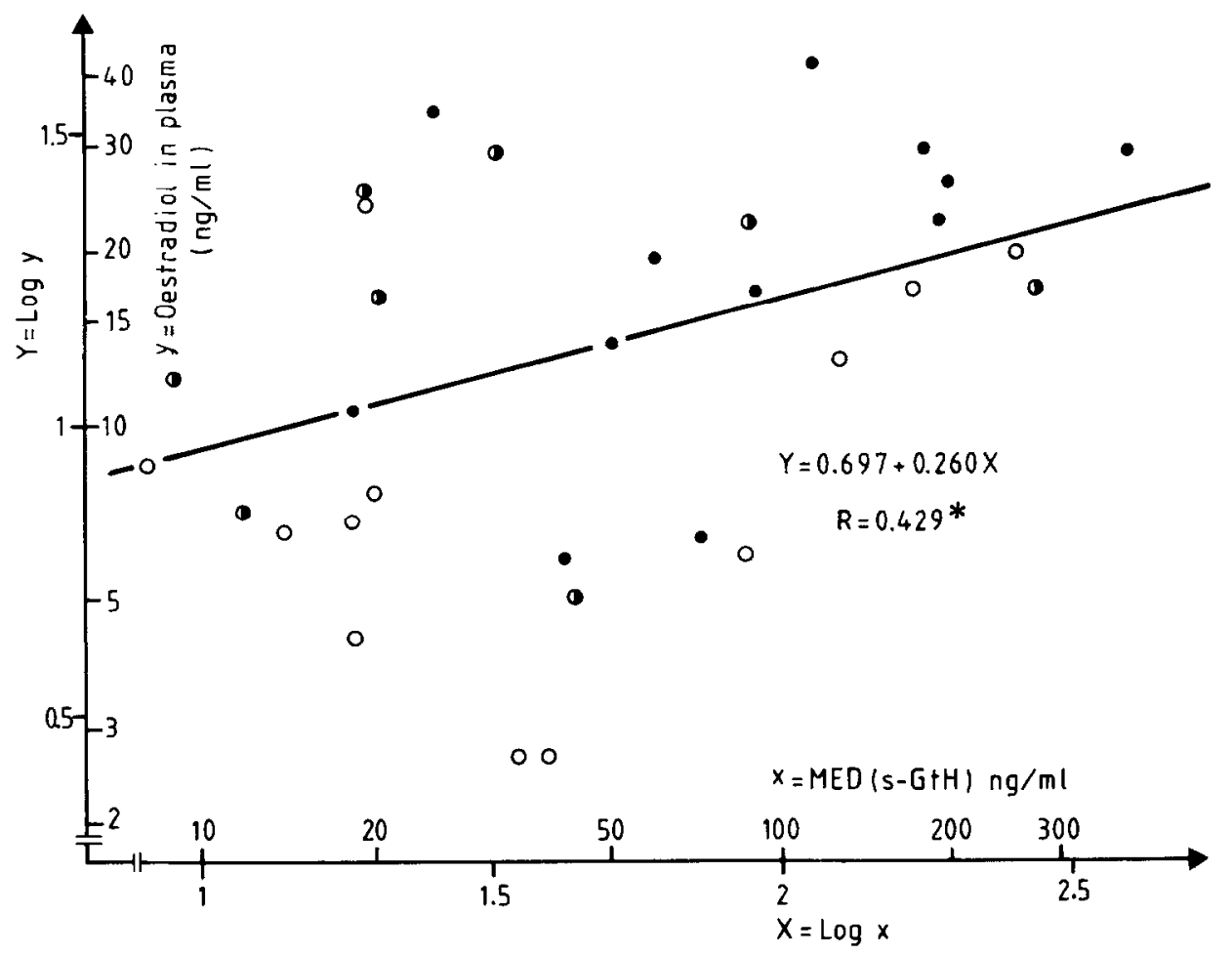

Fig. 3. Relationship between the MED of s-GtH for intrafollicular maturation and E2 level in the plasma of donor fishes. Same transformation of data and symbols as in Fig. 2. 
be drawn between the log-transformed co-ordinates, whose slope is significantly different from zero for doses of $\mathrm{E} 2$ of $1 \mu \mathrm{g}$ and $0.2 \mu \mathrm{g} / \mathrm{ml}$, but not for dose $0.04 \mu \mathrm{g} / \mathrm{ml}$ at which fewer experiments were performed. No discrimination between fishes at different stages could be made on a statistical basis because of insufficient data.

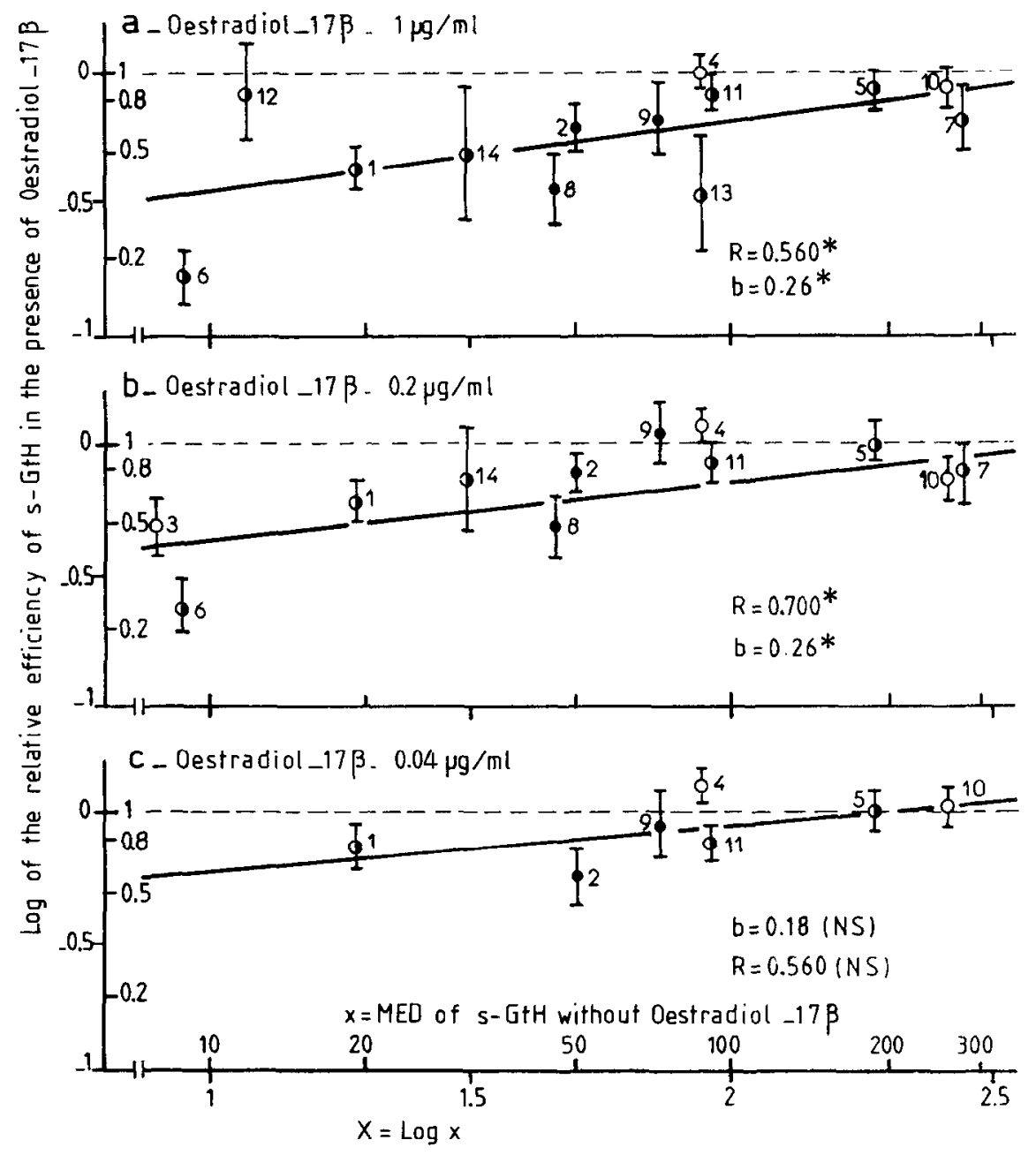

Fig. 4. Relationship between the relative efficiency of s-GtH in the presence of oestra-

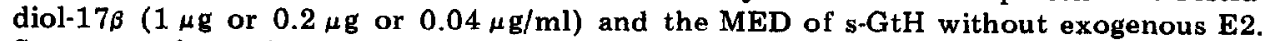
Same transformation of data as in Fig. 2. Vertical bars indicate the confidence limits $(P=0.95)$ of relative efficiency. 


\section{DISCUSSION}

It is obvious that the parameters taken into account, i.e., the different levels of follicular sensitivity to hormone in vitro and the level of oestradiol- $17 \beta$ in the plasma of donor fishes, exhibit a great variability between different fishes. Thus the morphological criterion of the germinal vesicle position does not offer a reliable classification of the fishes. An explanation might be that our estimations of follicular sensitivity, particularly to s-GtH, are based on the observation of a phenomenon - oocyte maturation - which comes at the end of a chain of mechanisms and can only reflect the result of complex interactions between multiple regulation factors, most of which are unknown. On the other hand, taking into account that GV migration to the oocyte periphery is in fact a progressive phenomenon, the assignment of a morphological stage to a fish necessarily represents an arbitrary character, particularly when the limit between stages is concerned. Nevertheless, some conclusions may be made from our data.

First, a morphological criterion, i.e., GV peripheral migration, appears clearly to be associated with an increase in oocyte sensitivity to $17 \alpha, 20 \beta$ OH-P (with the hypothesis that this is conveniently estimated from observed follicular sensitivity in vitro to $17 \alpha, 20 \beta-\mathrm{OH}-\mathrm{P})$. Thus, although oocyte sensitivity to $17 \alpha, 20 \beta-\mathrm{OH}-\mathrm{P}$ and follicular sensitivity to s-GtH show an overall significant covariation, the final migration of the germinal vesicle at the oocyte periphery introduces a discontinuity in this covariation which corresponds to an increase in oocyte responsiveness to $17 \alpha, 20 \beta-\mathrm{OH}-\mathrm{P}$ for a similar follicular sensitivity to gonadotropin. Moreover, taking into account that the observed sensitivity to s-GtH integrates, in fact, the sensitivity of the follicular tissue to $\mathrm{GtH}$ and the oocyte sensitivity to $17 \alpha$,$20 \beta-\mathrm{OH}-\mathrm{P}$, the increase in oocyte sensitivity to $17 \alpha, 20 \beta-\mathrm{OH}-\mathrm{P}$ occurring during final GV peripheral migration is probably underestimated.

The second important point is that the follicular sensitivity to s-GtH is negatively correlated with the plasma E2 level of the donor fish. This is in agreement with our former observation that $\mathrm{E} 2$ is able to lower $\mathrm{GtH}$ efficiency upon intrafollicular oocyte maturation in vitro (Jalabert, 1975) - an action which was recently shown to be associated with a partial inhibition of $17 \alpha, 20 \beta-O H-P$ output from the follicle (Jalabert and Fostier, 1984). This is further supported by the observation by Young et al. (1983) that the aromatase activity in the granulosa layers of amago salmon declines rapidly when the ability of the follicle to respond to salmon gonadotropin occurs. The absence of significant correlation between the follicular sensitivity to $17 \alpha, 20 \beta-\mathrm{OH}-\mathrm{P}$ and the level of oestradiol-17 $\beta$ in the plasma of donor fishes would agree with the fact that E2 does not seem to exhibit any modulating action in vitro upon $17 \alpha, 20 \beta-\mathrm{OH}$-P-induced maturation in trout (Jalabert, 1975). In contrast, E2 was shown to act at the oocyte level by modulating progesterone-induced maturation in Rana pipiens (Lin and Schuetz, 1983). 
Concerning the inhibitory action of E2 upon s-GtH-induced maturation observed here, this appears even more important since the follicles are more sensitive to GtH. A tentative explanation could be as follows: to exhibit the same maturational response, more sensitive oocytes are expected to require a lower amount of $17 \alpha, 20 \beta-\mathrm{OH}-\mathrm{P}$ than the others. If it is hypothesized that the inhibitory potency of a given concentration of E2 over GtH-induced $17 \alpha, 20 \beta-\mathrm{OH}-\mathrm{P}$ synthesis is constant, then the apparent inhibitory effect of E2 over intrafollicular GtH-induced maturation would be amplified in the follicles containing the more sensitive oocytes.

Finally, the fact that a concentration of oestradiol- $17 \beta$ as low as 40 $\mathrm{ng} / \mathrm{ml}$, which is in the physiological range, can inhibit significantly s-GtHinduced maturation in some fishes favors the hypothesis that E2 could be a main regulator of follicular sensitivity to $\mathrm{GtH}$, regarding $17 \alpha, 20 \beta$ OH-P synthesis ability.

The fact that the oocytes and the follicular envelopes constitute two different compartments which can exhibit an asynchronous differentiation has already been underlined (Schuetz, 1974) and was experimentally confirmed in the amphibian Xenopus laevis (Reynhout et al., 1975). This seems also to be the case in trout: on the one hand, the oocyte sensitivity to $17 \alpha, 20 \beta-\mathrm{OH}-\mathrm{P}$ appears to increase as a result of its own differentiation, characterized morphologically by the peripheral migration of the germinal vesicle; on the other hand, the ability of the follicular envelopes to synthesize $17 \alpha, 20 \beta-\mathrm{OH}-\mathrm{P}$ in response to the maturational gonadotropin GtH appears to be regulated by endocrinological cues (see Fostier and Jalabert, 1982). This certainly would allow some coupling between follicular differentiation and central modulation, in which oestradiol probably plays an important role.

\section{REFERENCES}

Breton, B., Prunet, P. and Reinaud, P., 1978. Sexual differences in salmon gonadotropin. Ann. Biol. Anim. Biochim., Biophys., 18: 759-765.

Finney, D.J., 1962. Probit Analysis. A Statistical Treatment of the Sigmoid Response Curve. Cambridge University Press, Cambridge, $333 \mathrm{pp}$.

Finney, D.J., 1964. Statistical Method in Biological Assay, 2nd edition. Charles Griffin and Company Ltd., London, $668 \mathrm{pp}$.

Fostier, A. and Jalabert, B., 1982. Physiological basis of practical means to induce ovulation in fish. Proc. Int. Reprod. Physiol. Fish. PUDOC, Wageningen, pp. 164-173.

Fostier, A. and Jalabert, B., 1983. Actions of gonadotropin or cyclic-AMP on steroid production in vitro by trout ovary prior to ovulation. XIIth Conf. Eur. Comp. Endocrinol., Sheffield (Abstr.).

Fostier, A., Jalabert, B. and Terqui, M., 1973. Action prédominante d'un dérivé hydroxylé de la progesterone sur la maturation in vitro des ovocytes de la Truite arcen-ciel, Salmo gairdnerii. C.R. Acad. Sci., Paris, 277: 421-424.

Fostier, A., Weil, C., Terqui, M., Breton, B. and Jalabert, B., 1978. Plasma estradiol-17 $\beta$ and gonadotropin during ovulation in rainbow trout (Salmo gairdneri R.). Ann. Biol. Anim., Biochim., Biophys., 18: 929-936. 
Goetz, F.W., 1983. Hormonal control of oocyte final maturation and ovulation in fishes. In: W.S. Hoar and D.J. Randall (Editors), Fish Physiology, Vol. IXB. Academic Press, New York, NY, pp. 117-170.

Jalabert, B., 1975. Modulation par différents stéroídes non maturants de l'efficacité

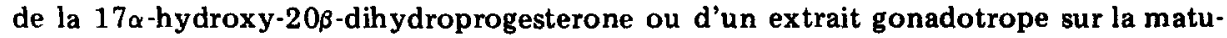
ration intrafolliculaire in vitro des ovocytes de la Truite arc-en-ciel Salmo gairdnerii. C.R. Acad. Sci., Paris, 281: 811-814.

Jalabert, B., 1976. In vitro oocyte maturation and ovulation in rainbow trout (Salmo gairdneri), northern pike (Esox lucius), and goldfish (Carassius auratus). J. Fish. Res. Board Can., 33: 974-988.

Jalabert, B. and Fostier, A., 1984. The modulating effect in vitro of oestradiol-17 $\beta$, testosterone or cortisol on the output of $17 \alpha$-hydroxy-20 $\beta$-dihydroprogesterone by rainbow trout (Salmo gairdneri) ovarian follicles stimulated by the maturational gonadotropin s-GtH. Reprod. Nutr. Dev., 24: 127-136.

Jalabert, B., Breton, B. and Billard, R., 1974, Dosage biologique des hormones gonadotropes de poissons par le test de maturation in vitro des ovocytes de Truite. Ann. Biol. Anim., Biochim., Biophys., 14: 217-228.

Lin, Y.W. and Schuetz, A.W., 1983. In vitro estrogen modulation of pituitary and progesterone-induced oocyte maturation in Rana pipiens. J. Exp. Zool., 226 : 281-291.

Reynhout, J.K., Taddei, C., Smith, L.D. and La Marca, M.J., 1975. Response of large oocytes of Xenopus laevis to progesterone in vitro in relation to oocyte size and time after previous HCG-induced ovulation. Dev. Biol., 44: 375-379.

Schiller, H.S., Hassel-Brack, R., Riggs, R.S. and Brammel, M.A., 1976. A faster radioimmunoassay of progesterone in plasma with use of polyethylene glycol as precipitant. Clin. Chem. (Winston Salem, NC), 22: 1659-1663.

Schuetz, A.W., 1974. Role of hormones in oocyte maturation. Biol. Reprod., 10: 150178.

Young, G., Kagawa, H. and Nagahama, Y., 1983. Evidence for a decrease in aromatase activity in the ovarian granulosa cells of Amago Salmon (Oncorhynchus rhodurus) associated with final oocyte maturation. Biol. Reprod., 29: 310-315. 